\title{
Facilitating Upper Limb Function using Assistive Technology in a Neurological Patient with Bilateral Upper Limb Impairment: A Case Report
}

Shelley Fulton

The Queen Elizabeth Hospital, shelley.fulton@sa.gov.au

Laura Wilkinson

The Queen Elizabeth Hospital, Laura.Wilkinson@sa.gov.au

Kathy Stiller

Central Adelaide Local Health Network, kathy.stiller@sa.gov.au

Follow this and additional works at: https://nsuworks.nova.edu/ijahsp

Part of the Medicine and Health Sciences Commons

\section{Recommended Citation}

Fulton S, Wilkinson L, Stiller K. Facilitating Upper Limb Function using Assistive Technology in a Neurological Patient with Bilateral Upper Limb Impairment: A Case Report. The Internet Journal of Allied Health Sciences and Practice. 2020 Jan 01;18(4), Article 14.

This Case Study is brought to you for free and open access by the College of Health Care Sciences at NSUWorks. It has been accepted for inclusion in Internet Journal of Allied Health Sciences and Practice by an authorized editor of NSUWorks. For more information, please contact nsuworks@nova.edu. 


\title{
Facilitating Upper Limb Function using Assistive Technology in a Neurological Patient with Bilateral Upper Limb Impairment: A Case Report
}

\begin{abstract}
Purpose: A combination of a stroke and spinal cord injury adversely affecting both upper limbs is an unusual combination for a patient presenting for outpatient rehabilitation services. Although the management of these conditions in isolation is well documented, there is limited literature regarding rehabilitation for these conditions in combination, particularly the use of assistive technology in this setting. Methods: A case report is presented of a 53-year-old male referred for outpatient rehabilitation following a left-sided stroke, with resultant dense right sided hemiplegia. A pre-existing spinal cord injury had affected his left upper limb such that he had marked proximal weakness. This combination of impairments meant he was unable to perform even basic activities of daily living involving the upper limbs. A therapy program, led by an occupational therapist with support and input from the multi-disciplinary team, included the use of an assistive device (a mobile arm support) to facilitate functional upper limb activities. This greatly improved his ability to do upper limb functional activities. Conclusion: The use of an assistive device enabled the patient to engage in meaningful activities of daily living involving the upper limbs.
\end{abstract}

\section{Author Bio(s)}

Shelley Fulton, BAppSc(OT), is the Senior Occupational Therapist, Day Rehabilitation Service, The Queen Elizabeth Hospital, Adelaide, South Australia.

Laura Wilkinson, BAppSc(OT), is an Occupational Therapist, Day Rehabilitation Service, The Queen Elizabeth Hospital, Adelaide, South Australia.

Kathy Stiller, BAppSc(Physio), PhD, is Allied Health Research Coordinator, Central Adelaide Local Health Network, South Australia.

\section{Acknowledgements}

We would like to thank the patient involved for his written consent to report his case and all members of the Day Rehabilitation Service team involved in his care. 


\title{
1IVAHSP \\ The Internet Joưnal of Allied Health Sciences and Practice
}

Dedicated to allied health professional practice and education

Vol. 18 No. 4 ISSN 1540-580X

\section{Facilitating Upper Limb Function using Assistive Technology in a Neurological Patient with Bilateral Upper Limb Impairment: A Case Report}

\author{
Shelley Fulton ${ }^{1}$ \\ Laura Wilkinson ${ }^{1}$ \\ Kathy Stiller ${ }^{2}$
}

1. The Queen Ellizabeth Hospital

2. Central Adelaide Local Health Network

Australia

\begin{abstract}
Purpose: A combination of a stroke and spinal cord injury adversely affecting both upper limbs is an unusual combination for a patient presenting for outpatient rehabilitation services. Although the management of these conditions in isolation is well documented, there is limited literature regarding rehabilitation for these conditions in combination, particularly the use of assistive technology in this setting. Methods: A case report is presented of a 53-year-old male referred for outpatient rehabilitation following a left-sided stroke, with resultant dense right sided hemiplegia. A pre-existing spinal cord injury had affected his left upper limb such that he had marked proximal weakness. This combination of impairments meant he was unable to perform even basic activities of daily living involving the upper limbs. A therapy program, led by an occupational therapist with support and input from the multi-disciplinary team, included the use of an assistive device (a mobile arm support) to facilitate functional upper limb activities. This greatly improved his ability to do upper limb functional activities. Conclusion: The use of an assistive device enabled the patient to engage in meaningful activities of daily living involving the upper limbs.
\end{abstract}

Keywords: stroke; spinal cord injuries; activities of daily living; upper extremity; self-help devices. 


\section{INTRODUCTION}

The term "stroke" is broadly used to include infarction, ischemia, or hemorrhage of the brain, spinal cord, or retina. ${ }^{1}$ It can result in weakness, problems controlling or coordinating movements, difficulties swallowing, personality and behavioural changes, and problems with thinking, memory, and speaking. ${ }^{2}$ In 2017 there were over 475,000 people living with the effects of stroke in Australia, and many of these had a disability that impeded their ability to carry out activities of daily living (ADLs) unassisted. ${ }^{3}$ The total financial costs of stroke in Australia were estimated to be $\$ A 5$ billion in 2012, with productivity costs the largest cost component at $\$ A 3$ billion, healthcare costs estimated at $\$ A 881$ million and carer costs as $\$ A 222$ million. ${ }^{4}$ Spinal cord injury (SCI) refers to damage to the spinal cord that results in a loss of functional mobility or feeling. ${ }^{5}$ It can occur as a result of trauma (e.g. fall, car accident), a medical condition, or other back and spine conditions, and depending on the level of in $\mathrm{SCl}$, can result in sensory deficit, motor deficit (e.g. tetraplegia or paraplegia) and/or bladder/bowel dysfunction. ${ }^{5} \mathrm{SCl}$ can impose a heavy physical, psychological and economic burden on the involved person, their family, and society because of the associated long-term disability, morbidity, and an increased mortality risk. ${ }^{6}$ In 2009, the total economic costs in Australia for traumatic tetraplegia were estimated as being $\$ A 1.3$ billion and $\$ A 690$ million for traumatic paraplegia. ${ }^{7}$ These costs were mainly attributable to healthcare, attendant care, equipment, and modifications. ${ }^{7}$ It was estimated in 2012 that 420,271 Australians were living with a stroke, and approximately 15,000 Australians were living with a SCl in 2109.3,8

The management of stroke and $\mathrm{SCl}$ includes rehabilitation by a multi-disciplinary team to help those involved return to as normal a life as possible by regaining and relearning the skills of everyday living. Specifically, for the upper limbs, rehabilitation aims to improve hand-arm function and functional independence and reduce disability.9,10 Upper limb rehabilitation is most commonly provided by physiotherapists and occupational therapists and can include unilateral or bilateral arm training, biofeedback, brain stimulation, constraint induced movement therapy (stroke), repetitive task training, and the use of assistive technology. 9,10

Mobile arm supports are one type of assistive technology that have been used to enable people with upper limb weakness, particularly proximal weakness, to increase the functional use of their hand. ${ }^{11,12}$ Mobile arm supports most often comprise a mechanical device, mounted on a desk or other surface, that supports the weak proximal upper limb against gravity enabling the person to move their limb at the elbow and distally, thus facilitating ADLs such as feeding, hygiene, grooming, writing, and page turning. ${ }^{11-13}$ Mobile arm supports have been used for a variety of neuromuscular conditions including stroke, tetraplegia, GuillainBarre syndrome, muscular dystrophy, multiple sclerosis, and spinal muscular atrophy. ${ }^{11,13}$ Van der Heide et al, in a relatively recent literature review that provided an overview and categorization of arm supports, identified 104 dynamic arm supports. ${ }^{12}$ They categorized the devices based on their technical requirements (i.e., non-actuated, passively actuated, actively actuated, or using functional electrical stimulation) and/or their functionalities (i.e., tremor suppression, facilitation of anti-gravity movements, or assistance of specific joint motion). ${ }^{12}$ The continued use of assistive devices, such as mobile arm supports, in the home setting is influenced by factors such as the perceived functional benefit, the user's attitude towards technology, and the usability/convenience of the device. ${ }^{14,15}$

The purpose of this case report is to describe the use of a mobile arm support to improve upper limb functional ability in a patient with bilateral upper limb impairment as a result of stroke and SCl.

\section{CASE HISTORY}

The patient was a 53-year-old male referred to the Day Rehabilitation Service at The Queen Elizabeth Hospital (Adelaide, South Australia) in September 2018. He was of Asian descent, unable to speak or understand English, and in Australia on a working visa, with the latter meaning he had to pay for all of his medical care.

In May 2016 he had undergone a cervical laminoplasty and thoracic decompression which resulted in tetraplegia. This was at the C4 level and classified as level D (i.e., motor incomplete where motor function is preserved below the neurological level, and at least half [or more]) of key muscle functions below the neurological level of injury have a muscle grade $\geq 3$; International Standards for Neurological Classification of Spinal Cord Injury [ISNCSCI]). In April 2018 he suffered an acute infarct in the left posterior lentiform nucleus which developed four days after lumbar decompression surgery. Other past medical history included Type II diabetes, hypertension, ischemic heart disease, and coronary artery bypass surgery.

From a functional perspective, the tetraplegia in 2016 resulted in marked proximal weakness of the left upper limb, some left hand weakness, and patchy arm sensation, markedly limiting the functional use of his left upper limb. At this time, his right upper limb was fully functional, and using his left upper limb to stabilize objects, he was able to use his right upper limb to complete functional tasks. After the SCI in 2016, he was able to walk independently with a single point stick, was independent in all ADLs, lived at home with his wife, and worked full time running a business in China (work primarily completed via computer and phone). The stroke in 2018 resulted in a dense right hemiplegia, dysarthria, and reduced sensation in his right leg. Post-stroke, the patient spent

( The Internet Journal of Allied Health Sciences and Practice, 2020 
12 days on an acute inpatient stroke ward and four months at a dedicated metropolitan inpatient rehabilitation facility. He was discharged home and referred for ongoing therapy to the Day Rehabilitation Service. Because of his inability to speak or understand English, particular care was taken to establish and maintain good communication between the patient and therapy team, with an official interpreter present at all therapy sessions for the duration of time he received care at the Day Rehabilitation Service.

At the time of referral to the Day Rehabilitation Service in September 2018, he required full assistance for feeding, hygiene, showering, dressing, grooming, and all domestic tasks. Full assistance was also required for transferring from lying in bed to sitting on the edge of the bed and floor transfers. Close supervision was required for transfers from sit to stand, bed to chair, toilet, to a car, and whilst walking (single point stick). He was able to self-propel a manual wheelchair using his left foot on smooth flat surfaces. With respect to his upper limb muscle power, at the time of referral, his right arm was severely affected by the stroke while the left arm had marked proximal weakness from the pre-existing SCI (Table 1). His upper limb muscle power at the time of discharge from the Day Rehabilitation Service was not discernibly different from that seen at referral (Table 1). His cognition was normal.

Table 1. Upper limb muscle power (manual muscle testing) at referral

\begin{tabular}{|cl|c|c|}
\hline \multicolumn{1}{|c|}{} & Left (SCl-affected side) & Right (stroke-affected side) \\
\hline Shoulder & & $1 / 5$ \\
& Flexion & $1 / 5$ & $2 / 5$ \\
& Extension & $0 / 5$ & $1 / 5$ \\
& Abduction & $0 / 5$ & $1 / 5$ \\
& Adduction & $0 / 5$ & \\
\hline Elbow & & $0 / 5$ & $2 / 5$ \\
& Flexion & $0 / 5$ & $1 / 5$ \\
& Extension & & \\
Wrist & & $4 / 5$ & $0 / 5$ \\
& Flexion & $4 / 5$ & $0 / 5$ \\
& Extension & $3 / 5$ & $0 / 5$ \\
& Pronation & $0 / 5$ & $0 / 5$ \\
& Supination & & \\
\hline Hand & Grip & $5 / 5$ & $0 / 5$ \\
& Thumb & $5 / 5$ & $0 / 5$ \\
& Fingers & $5 / 5$ & $0 / 5$ \\
\hline
\end{tabular}

The patient received a multi-disciplinary outpatient program four times a week for a total of three months from the Day Rehabilitation Service. The main therapists providing the Day Rehabilitation Service interventions were an occupational therapist, physiotherapist, exercise physiologist, and allied health assistant. His primary rehabilitation goals at this time were to improve balance when standing and walking, walking endurance, left upper limb function to enable eating, drinking, writing, and using a phone (with setup assistance), and right upper limb function to assist with stabilizing in tasks.

The occupational therapy interventions focused on improving upper limb function but after 3-4 weeks of therapy, no significant functional gains had been made: he was still unable to use his left SCl-affected arm functionally or use his right stroke-affected arm to stabilize during functional tasks. Therefore, a new intervention, namely a mobile arm support (Saebo Mobile Arm Support [SaeboMAS]), was commenced with the aim of improving his left SCl-affected upper limb function by supporting the weakened proximal upper limb. The SaeboMAS device was chosen because it is a passively actuated device (i.e., does not require external energy) that had the potential to support shoulder and elbow movement for this patient with minimal shoulder/elbow function, thereby facilitating distal upper limb function. ${ }^{12}$ Also, we were aware of its existence from colleagues, we were able to borrow one from a local metropolitan hospital for initial trial and then obtain one free of charge from a Sydney equipment supplier for a longer term trial period. The first two 45-minute therapy sessions focused on how best to set-up the mobile arm support to use within his functional impairment. This included trialling the mobile arm support being fixed to his wheelchair or a variable height therapy table, with the patient preferring the latter as a table was where he intended to complete the majority of his upper limb ADLs. This was followed by four further 45-minute practice sessions over the next few weeks aimed at increasing the range of functional activities he could perform and improving his confidence with using the device. Initially, therapy sessions with the device focused on tasks undertaken at the table-top level (e.g. writing, buttering bread) followed by more complex tasks. All tasks were learnt with comparative ease.

(c) The Internet Journal of Allied Health Sciences and Practice, 2020 
The device was set up on a variable height therapy table which was adjusted to enable use from a seated position. The patient required assistance to position his left arm into the forearm support of the device and fix the support strap. The SaeboMAS includes a tension scale (1-15 where $1=$ least amount of tension/support and $15=$ greatest amount of tension/support) which allows adjustment of the amount of support during various tasks. For this patient, the initial tension setting used was 5 and adjusted as required. For example, when combing his hair, where greater shoulder flexion was required, the tension was increased to 9 , whereas for table-top activities (e.g. writing, buttering bread) the tension was 5. Initially, the therapy team were unsure whether the patient would have sufficient shoulder and elbow extension strength to bring the arm strapped into the mobile arm support down to table height, against the device's resistance. However, in practice this was not problematic and, within minutes of its commencement, it became evident that the mobile arm support, by counteracting gravity, overcame the patient's marked left proximal upper limb weakness, positioned his hand in a functional position, enabling him to grasp and release items and move his hand in space, including to his mouth.

Various general outcome measures were collected, as per our usual clinical practice, at the time of referral to, and discharge from, the Day Rehabilitation Service with the assistance of the official interpreter. These were Lawton's Instrumental Activities of Daily Living Scale which measures the person's ability to participate in ADLs, the 10 Metre Walk test which is used to assess walking speed over a short distance, the Six Minute Walk Test to assess aerobic capacity and endurance, the Berg Balance Scale which determines a person's ability to safely balance during a series of pre-determined tasks and the Functional Independence Measure (FIM) which is used to assess the level of disability. ${ }^{16-20}$ As summarised in Table 2, improvements were seen over time in all but the cognitive domain of the FIM, although the magnitude of the improvements was mostly limited.

Table 2. General outcomes at referral and discharge from the Day Rehabilitation Service

\begin{tabular}{|l|c|c|}
\hline Outcome & At referral & At discharge \\
\hline Lawton's Instrumental Activities of Daily Living Scale score (8-30) & 13 & 15 \\
\hline 10 Metre Walk Test, time to complete, seconds & 76 & 36 \\
& & 75 \\
\hline Six Minute Walk Test, distance (meters) & Unable to complete & 35 \\
\hline Berg Balance Scale score (0-56) & 33 & \\
& & 78 \\
\hline Functional Independence Measure score & 67 & 43 \\
Total (18-126) & 32 & 35 \\
Motor (13-91) & 35 & \\
Cognitive (5-35) & & \\
\hline
\end{tabular}

Specific upper limb outcome measures were recorded, with the assistance of the official interpreter, at the time of referral and discharge from the Day Rehabilitation Service, with the latter measured whilst using the SaeboMAS. These outcomes comprised the Box and Block Test which measures unilateral gross manual dexterity, the Nine-Hold Peg Test to measure finger dexterity and the advanced hand activities domain of the Motor Assessment Scale which is used to assess everyday motor function. 21-23 Additionally, the patient was asked to rate his ability to undertake basic upper limb ADLs. As shown in Table 3, all upper limb outcome measures showed substantial improvement at discharge when using the mobile arm support. Figures 1-3 depict the patient undertaking various ADLs with and without the SaeboMAS.

Table 3. Upper limb outcome measures at referral and discharge from the Day Rehabilitation Service

\begin{tabular}{|l|c|c|}
\hline Outcome & $\begin{array}{c}\text { At referral } \\
\text { (not using SaeboMAS) }\end{array}$ & $\begin{array}{c}\text { At discharge } \\
\text { (using SaeboMAS) }\end{array}$ \\
\hline Box and Block Test, number of blocks moved in 60 seconds & 28 & 40 \\
\hline Nine-Hole Peg Test, time to complete test, seconds & 57 & 39 \\
\hline $\begin{array}{l}\text { Advanced Hand Activities domain of the Motor Assessment } \\
\text { Scale score }(0-6)\end{array}$ & 2 & 6 \\
\hline
\end{tabular}

(c) The Internet Journal of Allied Health Sciences and Practice, 2020 


\begin{tabular}{|c|c|c|}
\hline Basic ADLs score (1-10) $^{*}$ & 1 & 8 \\
Shaving & 1 & 5 \\
Combing hair & 1 & 8 \\
Eating with a spoon & 2 & 7 \\
Buttering bread & 1 & 8 \\
Drinking from a cup & 3 & 7 \\
Writing & 3 & \\
\hline
\end{tabular}

* self-rated by patient on a 1-10 verbal analogue scale (1 = extremely poor, cannot do; 10 = do extremely well).

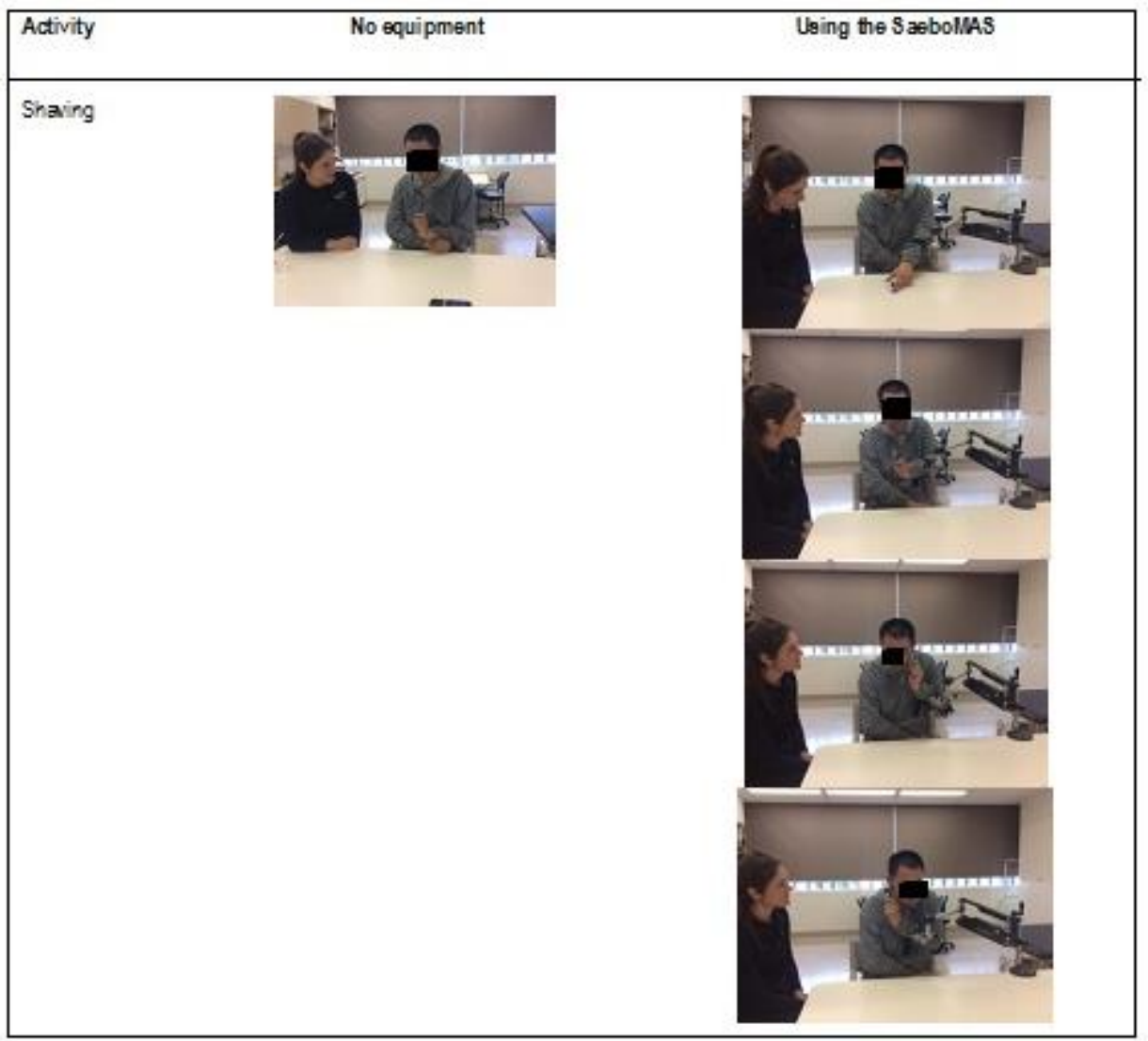

Figure 1. Shaving without/with device

Given the success of the mobile arm support at improving his upper limb functional ability, the patient privately purchased a SaeboMAS mini, a more compact version that works in the same way as the SaeboMAS, for $\$ A 7,459$. The patient embedded the use of the SaeboMAS mini into his upper limb ADLs at home. To facilitate this transfer of skills to the patient's own home environment, a single occupational therapy session was provided to the patient, in his own home once the device had been delivered. This 60-minute session focused on set-up of the mobile arm support on his own table and practice of ADL skills using the mobile arm support.

\section{Other Management}

The patient's progress was reviewed regularly at multi-disciplinary case conferences. Physiotherapy interventions focused on increasing his mobility. This included improving hip flexion power in order to create forward momentum in gait, because of his inability to generate any propulsion from his plantarflexors. This was achieved through practice of the swing phase, trampoline, gait retraining with and without a walking stick and standing balance exercises. The exercise physiology interventions focused on increasing lower and upper limb strength and endurance and cardiovascular fitness to assist with mobility progression. Initial limiting factors were fatigue, deconditioning, poor endurance, and reduced exercise tolerance, all of which improved over time. The patient also followed a comprehensive home exercise program for his therapy programs. 
The physiotherapist was allocated as the key case worker and took a lead role in communication and case-management with the patient and his family. This was particularly important given his complex medical history and that English was not his primary language. The patient was discharged from the Day Rehabilitation Service to receive private occupational therapy and physiotherapy follow-up.

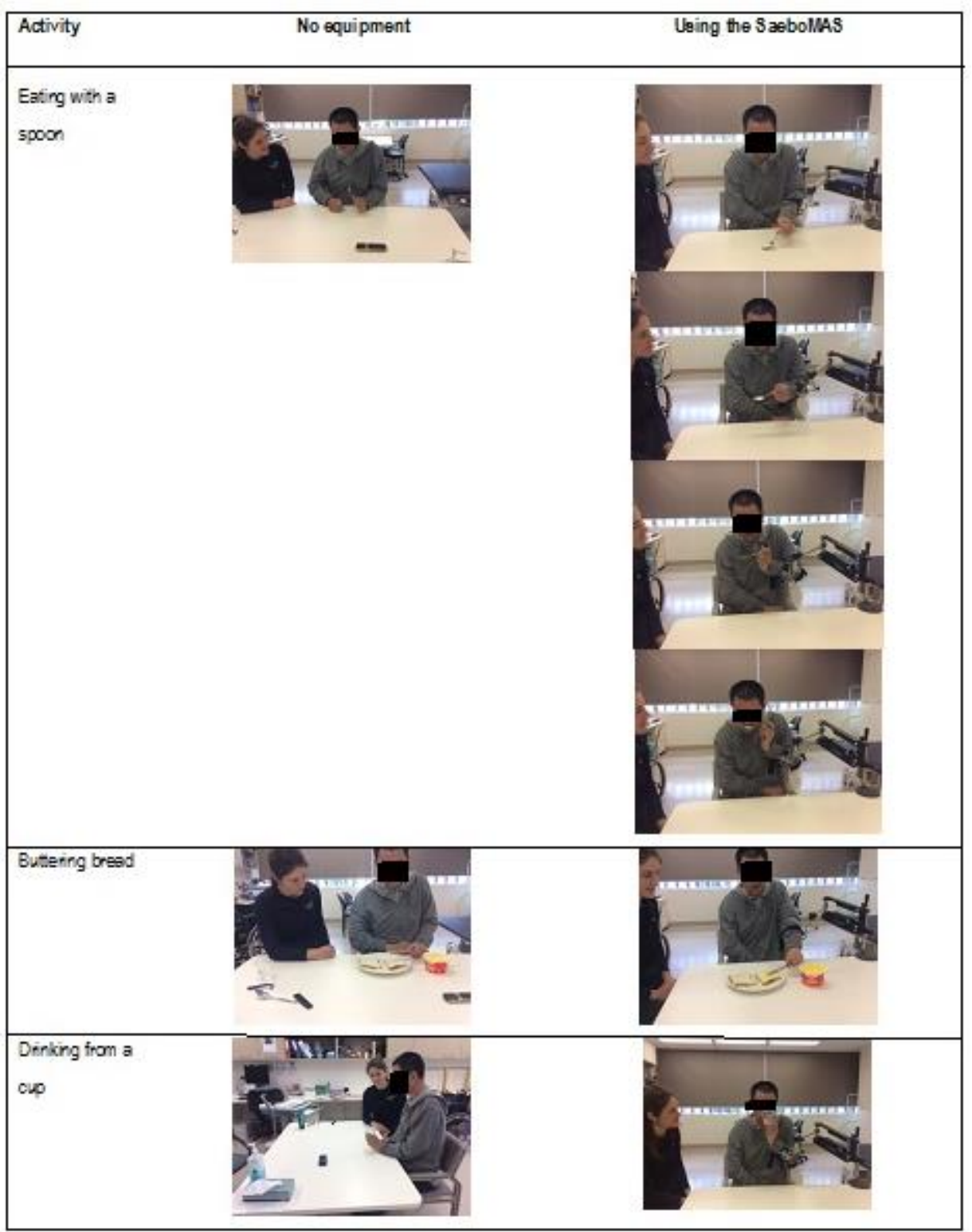

Figure 2. Eating with a fork, buttering bread, drinking from a cup without/with the device 


\begin{tabular}{|l|l|}
\hline Activity & No equipment \\
\hline Whiting
\end{tabular}

Figure 3. Writing without/with the device

\section{Longer-term Follow-up}

In order to obtain longer-term outcomes regarding the usefulness of the mobile arm support, the patient was reviewed in August 2019 by one of the investigators (SF), nine months following discharge from the Day Rehabilitation Service, with the patient's nephew acting as interpreter. The patient indicated that he was still using the mobile arm support daily, for an average of two hours per day, mainly for eating and electronic devices (iPad and mobile phone). He reported that he had returned to his previous occupation, with the SaeboMAS mini used occasionally for work-related tasks. As his partner was not present at this most recent visit, it was not possible to evaluate whether the device had reduced carer burden. His comments regarding the SaeboMAS mini included:

- "Recommend the device, it has been very helpful for me."

- "There are a lot of things I can do with the help of the device."

- "The biggest thing it has enabled me to do is lift my left arm, which means I can eat by myself, and do other things like clean my teeth."

\section{DISCUSSION}

This case report describes the effective use of a mobile arm support, the SaeboMAS, in an unusual presentation of a patient with bilateral upper limb impairment as a result of a stroke and pre-existing $\mathrm{SCl}$. The use of a mobile arm support enabled the patient to greatly increase the functional use of his left upper limb. Importantly, the patient has been able to embed the use of the mobile arm support into his daily activities at home long-term.

The keys to the success of this complex patient's care were that the involved therapists thought laterally and were willing to trial equipment seldom used in their usual clinical practice, and as a multi-disciplinary team, focused on working towards the patient's goals. There were a number of issues that had to be considered with the use of the mobile arm support for this patient. This included the high cost of the equipment as the patient we have reported was, by virtue of being in Australia on a work visa, obliged to pay for all of his care. Nevertheless, because of the functional benefits the mobile arm support provided, in terms of increasing his independence, the patient was willing and able to purchase the device. But for others the cost may be prohibitive if it is not covered by insurance or other funding sources. Another consideration regarding the device is that the patient we described will require ongoing set-up assistance and the device can only be used when set up on a table or bench, both of which limits its usability.

While the underlying presentation of the patient we have described was very unusual, his improved ability to undertake upper limb ADLs independently when using a mobile arm support is in keeping with previous research undertaken in other clinical settings, including stroke, $\mathrm{SCl}$, and spinal muscular atrophy.11,14,24 The limitations/difficulties of the mobile arm support that we encountered with this patient, such as the need for assistance with set-up and use being restricted to one setting only (i.e., table-top) is also in keeping with previous research. ${ }^{11,14}$ Previous research has found that the perceived functional benefit associated with using a mobile arm support appears to be particularly important with respect to its ongoing use, in that those with limited functional abilities benefit most whereas those experiencing less functional benefit are less likely to continue using the device. ${ }^{11}$ It has also been noted that longer-term adherence with using mobile arm supports and other assistive technology can be dependent on the balance between perceived functional benefit and usability issues.11,14,15 The continued longer-term use of the mobile arm support by the patient in this case report reinforces this finding, in that the mobile arm support enabled upper limb functional activities that otherwise would have been impossible and thus encouraged longer-term use of the device. It is also likely that the patient's positive attitude towards technology contributed to the success of the mobile arm support in our case report, as suggested in previous research. ${ }^{11}$ As technology improves it is likely that new devices with more intuitive interfaces, improved usability, and practical applicability will be developed to assist those with upper limb impairments. ${ }^{12,15}$

(C) The Internet Journal of Allied Health Sciences and Practice, 2020 


\section{Limitations}

The main limitation of this report is that it is a single case only, thus limiting its generalizability. Nevertheless, we believe this case report is interesting because of the unusual presentation of the patient with bilateral upper limb impairment resulting from a stroke and $\mathrm{SCl}$, which was unresponsive to usual therapy interventions. Formal research to investigate the use of mobile arm supports in this specific scenario, involving larger patient samples, would be extremely difficult given the unusualness of this presentation. We believe that a mobile arm support may be similarly effective for other patients who present with bilateral upper limb impairment, including unilateral upper limb proximal weakness, and thus of interest to healthcare professionals who may encounter patients with similar unusual combinations of problems. We acknowledge that our need to rely on an interpreter (official interpreter or nephew [longer-term follow-up]) to facilitate therapy and enable outcome measurements, whilst unavoidable, may have affected the validity of our results.

\section{CONCLUSION}

This case report, involving a patient with an unusual combination of neurological problems, demonstrated that a mobile arm support can be effective and should be considered as a therapy option for increasing upper limb function for any patient who presents with bilateral upper limb impairment, including unilateral proximal upper limb weakness.

\section{ACKNOWLEDGEMENTS}

We would like to thank the patient involved for his written consent to report his case and all members of the Day Rehabilitation Service team involved in his care.

\section{DECLARATION OF INTEREST}

The authors declare no conflict of interest. No funds were received from Saebo, and none of the authors are employees or contractors of this company.

\section{REFERENCES}

1. Sacco RL, Kasner SE, Broderick JP, et al. An updated definition of stroke for the 21st century: a statement for healthcare professionals from the American Heart Association/American Stroke Association. Stroke 2013;44(7):206489. [PMID: 23652265]

2. Stroke Foundation. Effects of stroke. Available at: https://strokefoundation.org.au/About-Stroke/Strokesymptoms/Effects-of-stroke. Accessed July 4, 2019.

3. Stroke Foundation. No postcode untouched. Stroke in Australia 2017. Available at: https://strokefoundation.org.au/en/What-we-do/Research/Research-resources/No-postcode-untouched. Accessed February 6, 2020.

4. Deloitte Access Economics (2013). The economic impact of stroke in Australia. National Stroke Foundation. Available at: https://www2.deloitte.com/au/en/pages/economics/articles/economic-impact-stroke-australia.html. Accessed July 4, 2019.

5. Spinal Cord Injuries Australia. What is a spinal cord injury? Understanding your injury. Available at: https://scia.org.au/what-is-a-spinal-cord-injury/. Accessed July 8, 2019.

6. Australian Institute of Health and Welfare. Tovell A (2018). Spinal cord injury, Australia, 2014-15. Injury research and statistics series no. 113. Cat. no. INJCAT 193. Canberra: AlHW. Available at: https://www.aihw.gov.au/getmedia/247d6e98-bf2f-408d-adbf-43db0bb5a7cf/aihw-injcat-193.pdf.aspx?inline=true. Accessed July 8, 2019.

7. Access Economics (2009). The economic cost of spinal cord injury and traumatic brain injury in Australia. Report by Access Economics Pty Limited for the Victorian Neurotrauma Initiative. Available at: http://www.spinalcure.org.au/pdf/Economic-cost-of-SCl-and-TBI-in-Au-2009.pdf. Accessed July 8, 2019.

8. Spinal Cord Injuries Australia. Summary of SCl statistics. Available at: https://scia.org.au/sci-statistics/. Accessed July 8, 2019.

9. Mateo S, Di Marco J, Cucherat M, Gueyffier F, Rode G. Inconclusive efficacy of intervention on upper-limb function after tetraplegia: a systematic review and meta-analysis. Ann Phys Rehabil Med 2019 Jun 21. pii: S18770657(19)30076-4. doi: 10.1016/j.rehab.2019.05.008. [Epub ahead of print] [PMID: 31233828]

10. Pollock A, Farmer SE, Brady MC, Langhorne P, Mead GE, Mehrholz J, van Wijck F. Interventions for improving upper limb function after stroke. Cochrane Database Syst Rev 2014 Nov 12;(11):CD010820. doi: 10.1002/14651858.CD010820.pub2.

11. Atkins MS, Baumgarten JM, Yasuda YL, Adkins R, Waters RL, Leung P, Requejo P. Mobile arm supports: evidencebased benefits and criteria for use. J Spinal Cord Med 2008;31(4):388-93. [PMID: 18959356] 
12. Van der Heide LA, van Ninhuijs B, Bergsma A, Gelderblom GJ, van der Pijl DJ, de Witte LP. An overview and categorization of dynamic arm supports for people with decreased arm function. Prosthet Orthot Int 2014;38(4):287302. [PMID: 23950551]

13. Kumar A, Phillips MF. Use of powered mobile arm supports by people with neuromuscular conditions. J Rehabil Res Dev 2013;51(1):61-70. [PMID: 23516084]

14. van der Heide $L$, de Witte $L$. The perceived functional benefit of dynamic arm supports in daily life. J Rehabil Res Dev 2016;53(6):1139-50. [PMID: 28355038]

15. van Ommeren AL, Smulders LC, Prange-Lasonder GB, Buurke JH, Veltink PH, Rietman JS. Assistive technology for the upper extremities after stroke: systematic review of users' needs. JMIR Rehabil Assist Technol 2018;5(2):e10510. [PMID: 30497993]

16. Australian Modified Lawton's IADL Scale. University of Wollongong, Australia. Available at: https://ahsri.uow.edu.au/aroc/lawtonsscale/index.html. Accessed July 11, 2019.

17. Ten Metre Walk Test. Physiopedia. Available at: https://www.physiopedia.com/index.php?title=10_Metre_Walk_Test\&oldid=211978. Accessed July 112019.

18. Six Minute Walk Test / 6 Minute Walk Test. Physiopedia. Available at: https://www.physiopedia.com/index.php?title=Six_Minute_Walk_Test__6_Minute_Walk_Test\&oldid=209618. Accessed July 15, 2019.

19. Berg Balance Scale. Physiopedia. Available at: https://www.physiopedia.com/index.php?title=Berg_Balance_Scale\&oldid=212042. Accessed July 11, 2019.

20. Functional Independence Measure (FIM). Physiopedia. Available at: https://www.physiopedia.com/index.php?title=Functional_Independence_Measure_(FIM)\&oldid=212112. Accessed July 11, 2019.

21. Box and Block Test. Physiopedia. Available at: https://www.physiopedia.com/index.php?title=Box_and_Block_Test\&oldid=204910. Accessed July 11, 2019.

22. Nine-Hole Peg Test. Physiopedia. Available at: https://www.physio-pedia.com/index.php?title=NineHole_Peg_Test\&oldid=204930. Accessed July 11, 2019.

23. Motor Assessment Scale. Physiopedia. Available at: https://www. physiopedia.com/index.php?title=Motor_Assessment_Scale\&oldid=204926. Accessed July 11, 2019.

24. Mehrholz J, Pohl M, Platz T, Kugler J, Elsner. Electromechanical and robot -assisted arm training for improving activities of daily living, arm function, and arm muscle strength after stroke. Cochrane Database Syst Rev 2018 Sep 3:9:CD006876. doi: 10.1002/14651858.CD006876.pub5. 